\title{
THE NATIONAL PARAPLEGIC CENTRE AT TOLEDO: ITS ORGANISATION AND ITS FUNCTION
}

\author{
By J. V. Forner, D.Phys.Med. \\ The National Paraplegic Centre at Toledo
}

ThE National Paraplegic Centre at Toledo was officially opened on 7 October I974 by the Prince of Spain, Juan Carlos. It is a Social Security hospital depending on the Minister of Labour D. Licinio de la Fuente. Sir Ludwig Guttmann together with many officials and doctors were present. He had previously been invited by the Government to give his expert advice on the setting up of the Centre together with several Spanish doctors and the architect.

The Centre has been built in order to give comprehensive treatment to the spinal injured patient from the moment of his accident until his social and professional resettlement has been achieved.

It is situated in Toledo, an old and beautiful town of 45,000 inhabitants, surrounded by the river Tajo, at $70 \mathrm{~km}$ from Madrid, and having a considerable artistic and historical interest.

The whole Centre will eventually have two parts: the first, which has already been completed, is the hospital for treatment and medical rehabilitation and the second part, which is about to be constructed, will consist of the workshops for vocational training, a hostel for chronic cases and a residence for staff members (fig. I).

\section{Architectural Aspects}

The medical part or hospital proper is built in an X-shaped form with a T-shaped extension stemming from the centre. Both buildings have three storeys and are connected by enclosed ramps easily negotiated by the patients in wheelchairs (fig. 2).

The capacity is of 226 beds and has been designed to be completely selfsufficient from other hospitals. There are also facilities to treat children with spina bifida.

On the ground floor are the administration offices, cafeteria, kitchen, medical library, post-mortem room, patients' receiving-room and out-patients department.

The first floor consists of four wings. Each wing has eleven rooms of one to three beds with a total capacity of 27 beds. Each room has its own sink and toilet, and each wing a dining and sitting room and two bathrooms.

The second floor is also divided into four wings. One of them has 17 beds with oxygen and suction facilities for tetraplegics and a fully equipped Intensive Care Unit containing four beds.

Another wing for children has 25 beds or cots and an Intensive Care Unit with six beds. The other two wings have 27 beds on each wing and are distributed in the same pattern as on the first floor.

The third floor is dedicated to general services with three operating rooms, pathological, biochemical and bacteriological laboratories and the departments of 


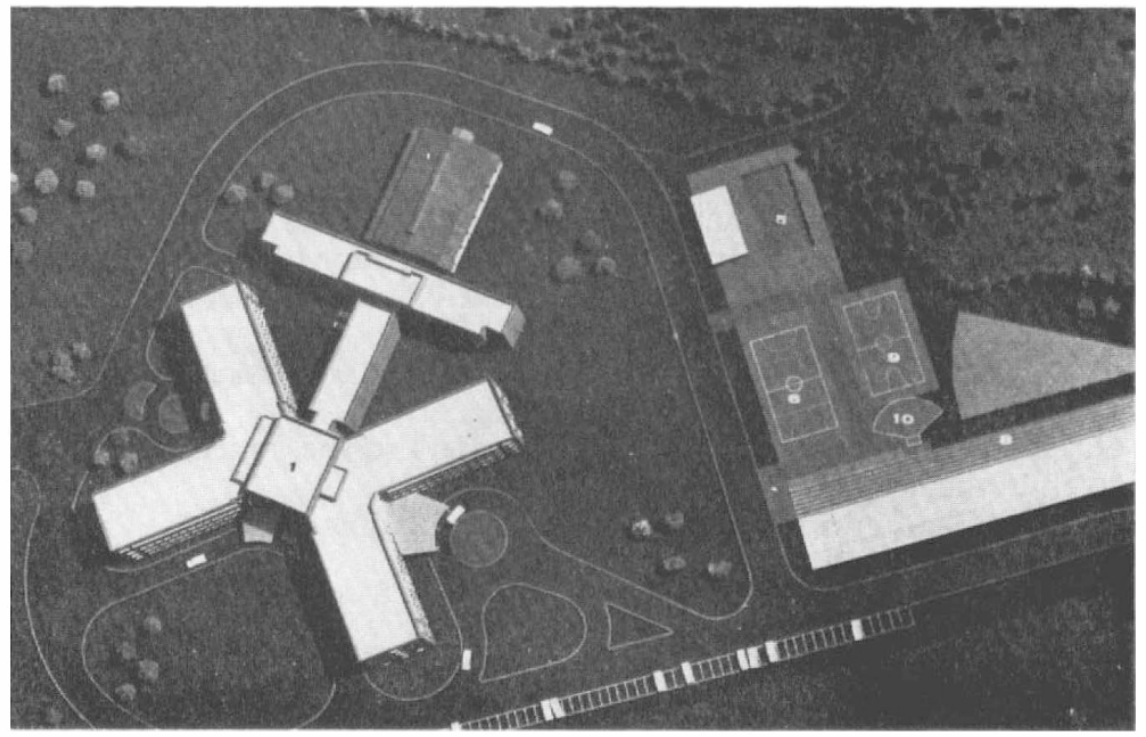

FIG. I

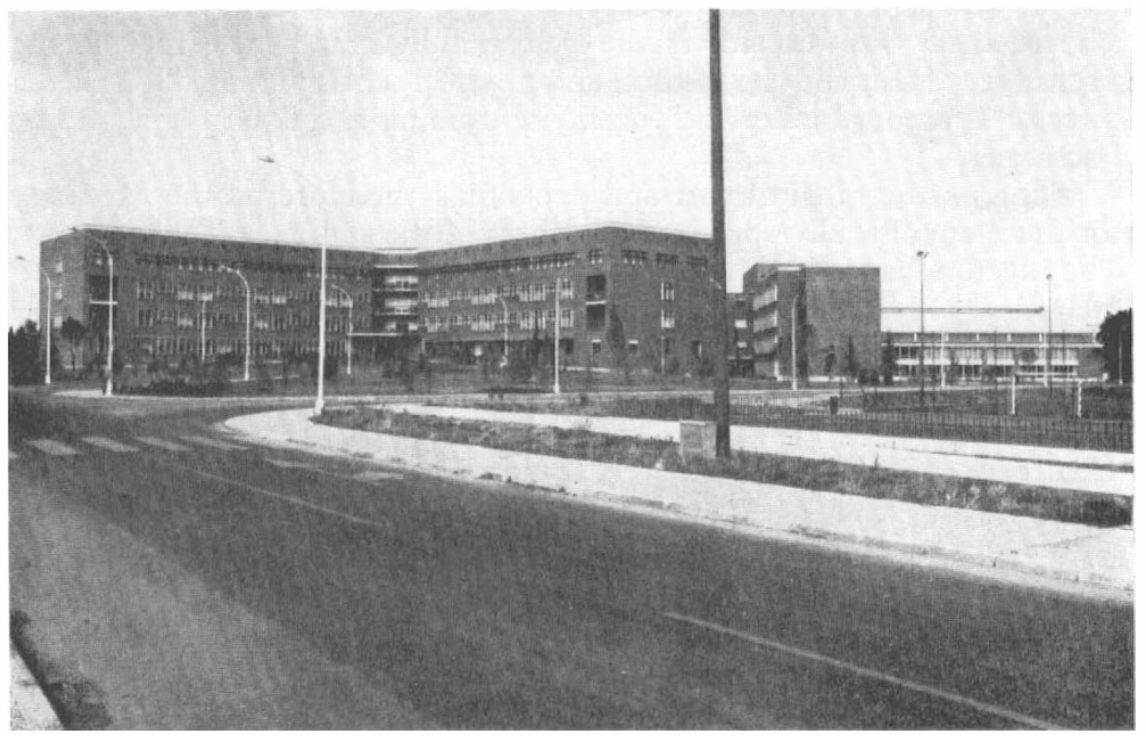

FIG. 2 
urology, respiratory testing, electromyography, electroencephalography, X-ray, psychiatry, psychology, opthalmology, odontology and ear nose and throat. Beside the operating theatre there is an Intensive Care Unit of 12 beds mainly to treat post-operative patients.

On one wing of the same floor there is a residence for 24 nurses.

On the ground floor of the T-shaped extension building are the physiotherapy department, the swimming pool and a large gymnasium which also serves as a lecture room, cinema, chapel and indoor sports area.

The three remaining floors contain the Occupational Therapy department, the school, library for patients, social services offices, photography department and two workshops for vocational training.

In the grounds of the Centre there are facilities for basket-ball, swimming, angling, archery, driving and wheelchair racing.

Of course, there are no architectural barriers so the patients can get about freely within the hospital grounds.

The total land area of the Centre is 100,000 square metres. The building area is 5400 square metres.

\section{Staff}

As we have mentioned before, the Centre is autonomous and is prepared to deal with the spinal patient from the moment of injury until his medical and vocational rehabilitation has been completed.

The Director of the whole Centre is a doctor who works in an administrative capacity without medical commitments.

Each of the two parts of the Centre has a Sub-director responsible for the organisation and supervision of the services.

The Medical Sub-director is the person fully responsible for the medical and surgical treatment and the medical and physical rehabilitation. The Technical Sub-director is reponsible for the vocational training and educational and recreational activities.

Working on the medical part and depending therefore on the Medical Subdirector there are officially approved members of the staff (see Table I). Table II).

The doctors are distributed according to specialties and categories (see

\section{Equipment}

The Centre is endowed with modern equipment for clinical work and also for medical research. I am not going to mention the various apparatus that we will have in the Centre as many of them have to be imported and have not yet been supplied. We have only to say that the authorities have been very generous.

\section{Functioning}

As I have been a member of the medical staff at Stoke-Mandeville Hospital, we follow the same lines of treatment set up by its Director, at that time Sir Ludwig Guttmann and later Dr J. J. Walsh. There is no point in describing these measures regarding the treatment of the spinal fracture and of the paralysed bladder as they are widely known. They are followed carefully at our Centre. 


\section{TABLE I}

Doctors

Registered nurses

42

Auxiliary nurses

Physiotherapists

Occupational therapists

Social workers

Orderlies

Administrative staff, Teachers and Auxiliary staff

Physical Medicine and

Rehabilitation

Respiratory Rehabilitation

Prothesis and Orthesiss

Surgery

Urology

Orthopaedics

Plastic Surgery

Anaesthetics

Internal Medicine

Paediatric

Neurology

Bacteriology

Laboratory

Radiology

Psychiatry

Psychology

Total

\section{TABLE II}

$\overbrace{\begin{array}{c}\text { Head } \\ \text { Department }\end{array}}^{\text {Sead }_{\text {Service }}^{\text {Senior }}} \begin{gathered}\text { Head } \\ \text { Section }\end{gathered}$

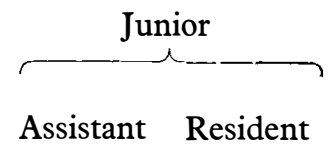

Total Senior, 20; Total Junior, 22.

\section{Research}

Although the hospital is equipped and planned to carry out medical research, at the present time there is no direct research being carried out, because the hospital has only been opened for several months and the medical staff are more concerned with clinical work and training of the nursing staff.

$$
\text { I4/I-F }
$$




\section{Training Programme}

Nevertheless there is a medical training programme in progress for postgraduates. There are six posts for residents on training during a three-year period after which they can obtain an Assistant's post. We hold daily meetings with the medical staff in order to maintain a uniform policy for dealing with the main problems of paraplegia. All medical staff are involved in the training of nursing staff.

We hope that very soon the Centre will be completed with the construction of the workshops for vocational training and residence.

By that time the comprehensive rehabilitation of our patients will be a reality.

We are nevertheless aware that there are some defects in the organisation of the Centre and we shall welcome any criticism that may help us to make the necessary corrections to treat our patients in the best possible way. 